Zhen Zhang • ChaoQun Wu • Wei Huang • Shu Wang

EnPeng Zhao • QingShan Huang • Yi Xie • YuMin Mao

\title{
A novel human gene whose product shares homology with bovine brain-specific protein p25 is expressed in fetal brain but not in adult brain
}

\begin{abstract}
We have cloned a novel human gene (C14orf5) from a fetal brain cDNA library that is located on chromosome 14 and consists of 4 exons. It encodes a protein of 170 amino acids that shares homology with human p25 alpha and bovine p25. Reverse transcription-polymerase chain reaction analysis indicated that it is highly expressed in liver and pancreas. Its transcripts could not be detected in adult brain but could be found in fetal brain.
\end{abstract}

Key words Bovine brain-specific p25 - Human p25 alpha cDNA cloning

A brain-specific protein, $\mathrm{p} 25$, was originally isolated from the partially purified fraction of bovine tau protein kinase II (Takahashi et al. 1991). The immunohistochemical studies showed that p25 was localized in oligodendrocytes and neuropils (Takahashi et al. 1993). Its complete cDNA sequence has been determined, but its function is still unknown (Shiratsuchi et al. 1995). Its counterpart in humans, p25 alpha, with which it shares $90 \%$ identity at the amino acid level, has been cloned, and it was found to be expressed ubiquitously rather than to be brain specific (Seki et al. 1999).

During the large-scale sequencing analysis of a human fetal brain cDNA library constructed in our lab (Xu et al. 2001), we isolated a novel cDNA clone that is $742 \mathrm{bp}$ long. It has an open reading frame from 168 to $638 \mathrm{bp}$ that encodes an $18.5 \mathrm{kDa}$ protein. The first ATG satisfies the Kozak consensus A/GXXATGG and the 5' untranslated region contains two in-frame stop codes. The polyadenylation signal (AATAAA) is located at 707 to $712 \mathrm{bp}, 16 \mathrm{bp}$ before the

Z. Zhang $\cdot$ C. Wu $\cdot$ W. Huang $\cdot$ S. Wang $\cdot$ E. Zhao $\cdot$ Q. Huang

Y. Xie - Y. Mao $(\square)$

State Key Laboratory of Genetic Engineering, Institute of Genetics, School of Life Sciences, Fudan University, Shanghai 200433, P. R.

China

Tel. +86-21-65643573; Fax +86-21-65642502

e-mail: ymmao@fudan.edu.cn
polyA tail. BLASTX searching with its putative amino acid sequence against the nonredundant sequence database in GenBank showed that it has $57 \%$ identity with both bovine p25 and human p25 alpha at the amino acid level. Additionally, it shares homology with five other putative proteins from human, mouse, fruit fly, and C. elegans (Fig. 1). There are several sites conserved in all these proteins, the most notable among them is the Rossmann motif GXGXXG, an ATP-binding site of protein kinases (Kemp and Pearson 1990), in that it is the only motif that can be found in all these proteins. In accordance with the suggestion of the Human Gene Nomenclature Committee, the gene was named C14orf5. Its sequence has been submitted to GenBank (accession number AY072034).

BLAST searching with its nucleotide acid sequences against the nonredundant sequences database in GenBank found a perfect match with human bacterial artificial chromosome (BAC) C-2552B11 (AL157687) and R-998D10 (AL161668) on chromosome 14. On the basis of these data, we established the exon-intron structure of the gene according to the AG-GT rule (Table 1 ), which shows that the gene has 4 exons. The BLAST result also revealed a sequence tagged site (STS) marker (STS65398) within the cDNA sequence (from 577 to $701 \mathrm{bp}$ ), by which the gene could be mapped to position 9.20 on Chromosome 14 of the GM 99 GB4 Map (cR 3000) (http://www.ncbi.nlm.nih.gov/ cgi-bin/Entrez/map_search/).

Human multiple tissue cDNA panel I and the tumor panel (Clontech, Palo Alto, CA, USA) were used as templates to investigate the expression pattern of the gene, according to the manufacture's protocol. The polymerase chain reaction (PCR) primers were designed for positions 472 and $690 \mathrm{bp}$ (sequences: CAGTGGACCGTTTGACAGACACC AGCA and GgtgTtAaACATGCAGGGTCAGGGGGC). A clear band between 200 and $300 \mathrm{bp}$ can be detected in several tissues and tumor cell lines (The bands smaller than $100 \mathrm{bp}$ are primer dimers). Among the normal tissues, the gene is highly expressed in liver and pancreas and has a moderate expression level in heart, skeletal muscle, and kidney. However, its transcript could not be detected in lung, placenta, or brain, even when the PCR cycle number was increased to 
Table 1. Exon-intron structure of C14orf5

\begin{tabular}{|c|c|c|c|c|c|}
\hline 3' Splice acceptor & Exon & Size (bp) & $5^{\prime}$ Splice donor & Intron & Size (bp) \\
\hline & 1 & 56 & GTACTCTAAGgtacataaaaga & 1 & 210 \\
\hline attactccacagТССТСССТСС & 2 & 242 & GCAAAGTCAAgtgaggagccaa & 2 & 259 \\
\hline ctaactgaccagGGCCAAGAAC & 3 & 154 & TGGCGCTACTgtgagtgacagc & 3 & 728 \\
\hline cetggcttgcagAAAGCAACAA & 4 & 276 & & & \\
\hline
\end{tabular}

The exon-intron boundaries were identified according to the Blastn results of the DNA sequence of C14orf5 against AL161668

All the boundaries are in accordance with GT-AG (in bold) rules. The residues of the exons are capitallized

Fig. 1. Multiple alignment of C14orf5 with its seven homologs. $N P \_057224$ : brain specific protein CGI-38 (Homo sapiens); $X P_{-}$ 043104: hypothetical protein (Homo sapiens); XP_003662: brain-specific protein p 25 alpha (Homo sapiens); NP_080757: RIKEN cDNA 2700055K 07 gene (Mus musculus); CAA59741: novel brain-specific protein p25 (Bos taurus); AAF49479: CG4893 gene product (Drosophila melanogaster); T25598: hypothetical protein C32E8.3 (Caenorhabditis elegans). Similar residues in at least three fourths of the sequences are shadowed (the residues conserved in all the sequences are indicated by a black background). The asterisks indicate the ATP-binding site of the protein kinases
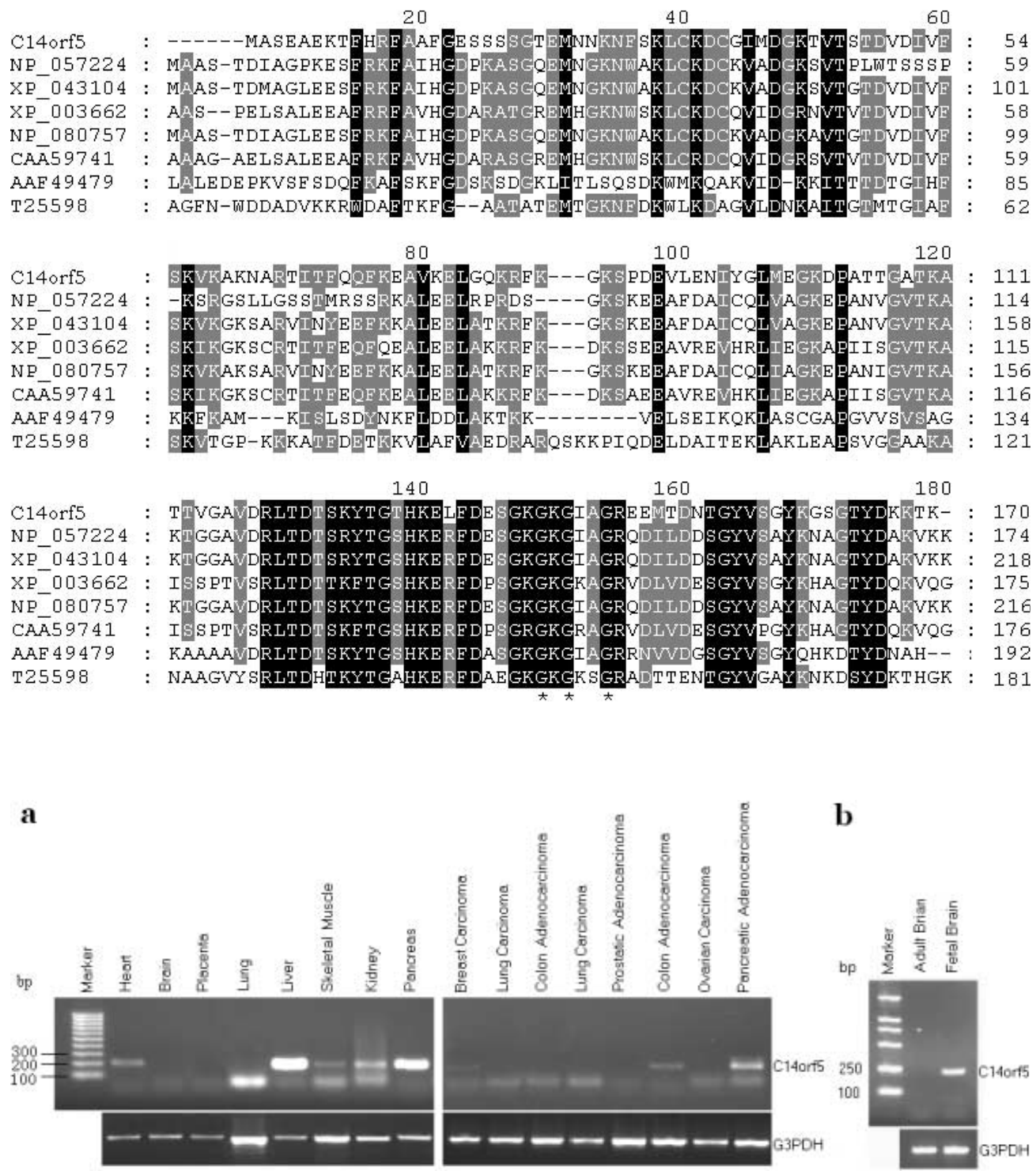

Fig. 2. a The expression pattern of C14orf5 in normal tissues and tumor cell lines. Twenty-five cycles (for $G 3 P D H$ ) or 38 cycles (for C14orf5) of amplification $\left(94^{\circ} \mathrm{C}, 30 \mathrm{~s}\right.$ and $\left.68^{\circ} \mathrm{C}, 90 \mathrm{~s}\right)$ were performed by using an Advantage 2 Kit (Clontech). The polymerase chain reaction (PCR) products of $C 14$ orf5 and G3PDH were then electrophoresed on a $1.8 \%$ agarose gel (FMC, Philadelphia, PA, USA). b The distribution of $C 14$ orf 5 in fetal and adult brain. The PCR conditions are the same as for a. The products of 30 cycles for G3PDH and 38 cycles for C14orf5 of amplification were electrophoresed
40. And among the tumor cell lines, the signal was detected only in breast carcinoma, pancreas adenocarcinoma, and one colon adenocarcinoma (Fig. 2a). In contrast to its homologs, such as p25 alpha, which is ubiquitously expressed (Seki et al. 1999), or bovine p25, which is brain specific
(Takahashi et al. 1991), the gene has a completely different expression pattern. Because the gene is not expressed in adult brain but was isolated from fetal brain, we used reverse transcription (RT)-PCR to examine its expression level in the latter. The PCR product could be detected only 
in fetal brain (Fig. 2b), which confirmed that it is expressed in fetal brain but not in adult brain. Further experiment is necessary to determine whether the gene plays a role in brain development.

\section{References}

Kemp BE, Pearson RB (1990) Protein kinase recognition sequence motifs. Trends Biochem Sci 15:342-346

Seki N, Hattori A, Sugano S, Suzuki Y, Nakagawara A, Muramatsu MA, Hori TA, Saito T (1999) A novel human gene whose product shares significant homology with the bovine brain-specific protein p25 on chromosome 5p15.3. J Hum Genet 44:121-122

Shiratsuchi A, Sato S, Oomori A, Ishiguro K, Uchida T, Imahori K (1995) cDNA cloning of a novel brain-specific protein p25. Biochim Biophys Acta 1251:66-68

Takahashi M, Tomizawa K, Ishiguro K, Sato K, Omori A, Sato S, Shiratsuchi A, Uchida T, Imahori K (1991) A novel brain-specific $25 \mathrm{kDa}$ protein (p25) is phosphorylated by a Ser/Thr-Pro kinase (TPK II) from tau protein kinase fractions. FEBS Lett 289:37-43

Takahashi M, Tomizawa K, Fujita SC, Sato K, Uchida T, Imahori K (1993) A brain-specific protein p25 is localized and associated with oligodendrocytes, neuropil, and fiber-like structures of the CA3 hippocampal region in the rat brain. J Neurochem 60:228-235

Xu J, Zhou Z, Zeng L, Huang Y, Zhao W, Cheng C, Xu M, Xie Y, Mao Y (2001) Cloning, expression and characterization of a novel human REPS1 gene. Biochem Biophys Acta. 1522:118-121 